\title{
Green Synthesis and Antibacterial Effect of Silver Nanoparticles Using Vitex Negundo L.
}

\section{Mohsen Zargar ${ }^{1,2}$, Azizah Abdul Hamid ${ }^{1,6, *}$, Fatima Abu Bakar ${ }^{1}$, Mariana Nor Shamsudin ${ }^{4}$, Kamyar Shameli ${ }^{5}$, Fatemeh Jahanshiri ${ }^{3}$ and Farah Farahani ${ }^{2}$}

1 Department of Food Science, Faculty of Food Science and Technology, Universiti Putra Malaysia, Selangor 43400, Malaysia; E-Mails: zmohsen2002@gmail.com (M.Z.); fatim@putra.upm.edu.my (F.A.B.)

2 Department of Biology, Qom Branch, Islamic Azad University, Qom, Iran; E-Mail: farahfarahani2000@yahoo.com

3 Faculty of Biotechnology and Biomolecular Science, Universiti Putra Malaysia, Selangor 43400, Malaysia; E-Mail: f.jahanshiri@gmail.com

4 Department of microbiology and parasitology, Faculty of Medicine, Universiti Putra Malaysia, Selangor 43400, Malaysia; E-Mail: mariana@medic.upm.edu.my

5 Department of Chemistry, Faculty of Science, Universiti Putra Malaysia, Serdang, Selangor 43400, Malaysia; E-Mail: kamyarshameli@gmail.com

6 Agro-Biotecnologi Institute Malaysia, Ministry of Science, Technology and Innovation of Malaysia, Selangor 43400, Malaysia

* Author to whom correspondence should be addressed; E-Mail: azizahhamid@ mosti.gov.my; Tel.: + 603-894319804; Fax: +603-89416229.

Received: 30 June 2011; in revised form: 19 July 2011 / Accepted: 19 July 2011 / Published: 8 August 2011

\footnotetext{
Abstract: Different biological methods are gaining recognition for the production of silver nanoparticles (Ag-NPs) due to their multiple applications. One of the most important applications of Ag-NPs is their use as an anti-bacterial agent. The use of plants in the synthesis of nanoparticles emerges as a cost effective and eco-friendly approach. In this study the biosynthesis of silver nanoparticles using Vitex negundo L. extract and its antimicrobial properties has been reported. The resulting silver particles are characterized using transmission electron microscopy (TEM), X-ray diffraction (XRD) and UV-Visible (UV-Vis) spectroscopic techniques. The TEM study showed the formation of silver nanoparticles in the 10-30 $\mathrm{nm}$ range and average $18.2 \mathrm{~nm}$ in size. The XRD study showed
} 
that the particles are crystalline in nature, with a face centered cubic (fcc) structure. The silver nanoparticles showed the antimicrobial activity against Gram positive and Gram negative bacteria. Vitex negundo L. was found to display strong potential for the synthesis of silver nanoparticles as antimicrobial agents by rapid reduction of silver ions $\left(\mathrm{Ag}^{+}\right.$to $\left.\mathrm{Ag}^{0}\right)$.

Keywords: green synthesis; silver nanoparticles; Vitex negundo; antibacterial activity; transmission electron microscopy

\section{Introduction}

Nanoparticles are often referred to as particles with a maximum size of $100 \mathrm{~nm}$. Nanoparticles exhibit unique properties, which are quite different than those of larger particles. New properties of nanoparticles related to variation in specific characteristics like size, shape and distribution have been demonstrated [1]. Among the noble metals (e.g., Ag, Pt, Au and Pd), silver (Ag) is the metal of choice for potential applications in the field of biological systems, living organisms and medicine [2]. Due to their exclusive properties, silver nanoparticles (Ag-NPs) may have several applications, such as catalysts in chemical reactions [3], electrical batteries and in spectrally selective coatings for absorption of solar energy [4,5], as optical elements [6], pharmaceutical components and in chemical sensing and biosensing [7,8]. Nanoparticle formation has been reported using chemical and physical methods. There are various methods for Ag-NPs formation such as sol-gel process, chemical precipitation, reverse micelle method, hydrothermal method, microwave, chemical vapour deposition and biological methods, etc [9-11].

Recently, biosynthetic methods have been investigated as a new way for the production of Ag-NPs. Biological methods are currently gaining importance because they are eco-friendly, cost effective, and don't involve the use of any toxic chemicals for the synthesis of nanoparticles [12-14]. The biosynthesis of inorganic nanomaterials has been performed using eukaryotic organisms such as fungi to produce nanoparticles of gold and silver $[15,16]$. Synthesis of nanosilver particles using ascorbic acid and citrate as reducing agents has recently been reported [17]. An earlier study showed that Shewanella algae was found able to reduce gold ions, forming 10-20 nm gold nanoparticles [18].

There have been several reports on the synthesis of Ag-NPs using medicinal plants such as Basella alba, Helianthus annus, Saccharum officinarum, Oryza sativa, Sorghum bicolour, Zea mays [19], Aloe vera [20], Medicago sativa (Alfalfa) [21], Capsicum annuum [22], Magnolia kobus [23], Cinnamomum camphora leaf [24], and Geranium sp. [25] for pharmaceutical and biological applications. A green synthesis of nanosilver particles using a methanolic extract of Eucalyptus hybrida leaves was reported [26]. Another study related to the synthesis of nanoparticles from Vitex negundo L. leaf extract in water solution with heat treatment [27]. A profile of bioactive compounds of Vitex negundo has been reported, which revealed that the plant contained a high amount of total phenolic compounds and flavonoids, which are considered to be potent natural antioxidants [28,29].

Recently, some studies have shown that specially formulated Ag-NPs have good antibacterial activity [30]. The bacteria usually are incapable of developing resistance against Ag-NPs, because these nanomaterials can at the same time attack a broad range of targets in microorganisms such as 
proteins with thiol groups, cell walls and cell membranes. A recent study on Escherichia coli has shown that Ag-NPs react with cell walls and cytoplasmic membranes, resulting in pits in the cell wall of bacteria, and finally killing them [31]. It has been reported that greenly synthesized titania $\left(\mathrm{TiO}_{2}\right)$ and silver nanocomposites (TANCs) can easily damage the cell walls of E. coli [32]. The antimicrobial and antiviral activity of silver ion, silver compounds and Ag-NPs have been thoroughly investigated in previous studies [33-35].

In this study, the synthesis and characterization of silver nanoparticles/Vitex negundo (Ag/Vitex negundo) by a green method reported. Ag-NPs were prepared using silver nitrate as silver precursor and methanol extract of Vitex negundo leaf as reducing agent and stabilizer. The antibacterial effect of Ag/Vitex negundo was evaluated against two pathogenic bacteria, including Escherichia coli (Gram negative) and Staphylococcus aureus (Gram positive) using the agar disc diffusion method.

\section{Results and Discussion}

Green synthesis of silver nanoparticles using $10^{-1} \mathrm{M}, \mathrm{AgNO}_{3}$ is shown in Figure 1. The fresh suspension of Vitex negundo was yellowish-green in colour. However, after addition of $\mathrm{AgNO}_{3}$ and stirring for $48 \mathrm{~h}$ at room temperature, the emulsion turned dark brown.

Figure 1. Photograph of (a) Vitex negundo and (b) Ag/Vitex negundo emulsion after $48 \mathrm{~h}$.

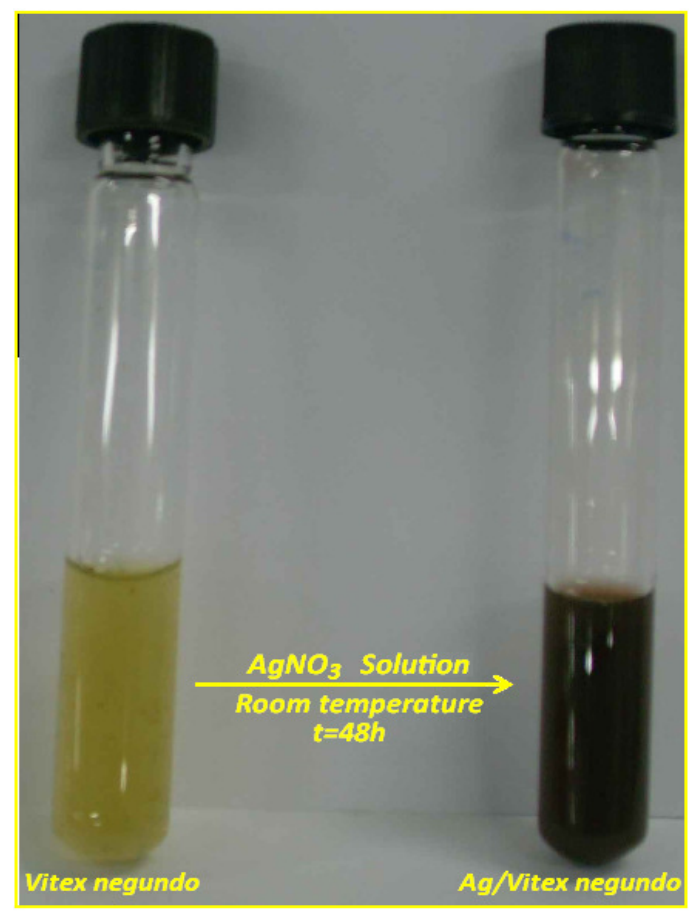

The formation of silver nanoparticles was followed by measuring the surface plasmon resonance (SPR) of the Vitex negundo and Ag/Vitex negundo emulsion at the wavelength range from 300-700 nm (Figure 2). The characteristic silver SPR bands were detected around 400-450 nm. These absorption bands were assumed to correspond to the silver nanoparticles extra fine and smaller than $25 \mathrm{~nm}$. UV-Vis absorption spectra (Figure 2b) showed that the broad SPR band contained two peaks, one at $422 \mathrm{~nm}$ and the other at $447 \mathrm{~nm}$. These two peaks illustrate the presence of two broad distribution of hydrosol silver nanoparticles. 
Figure 2. UV-Vis absorption spectra of (a) Vitex negundo and (b) Ag/Vitex negundo emulsion after $48 \mathrm{~h}$.

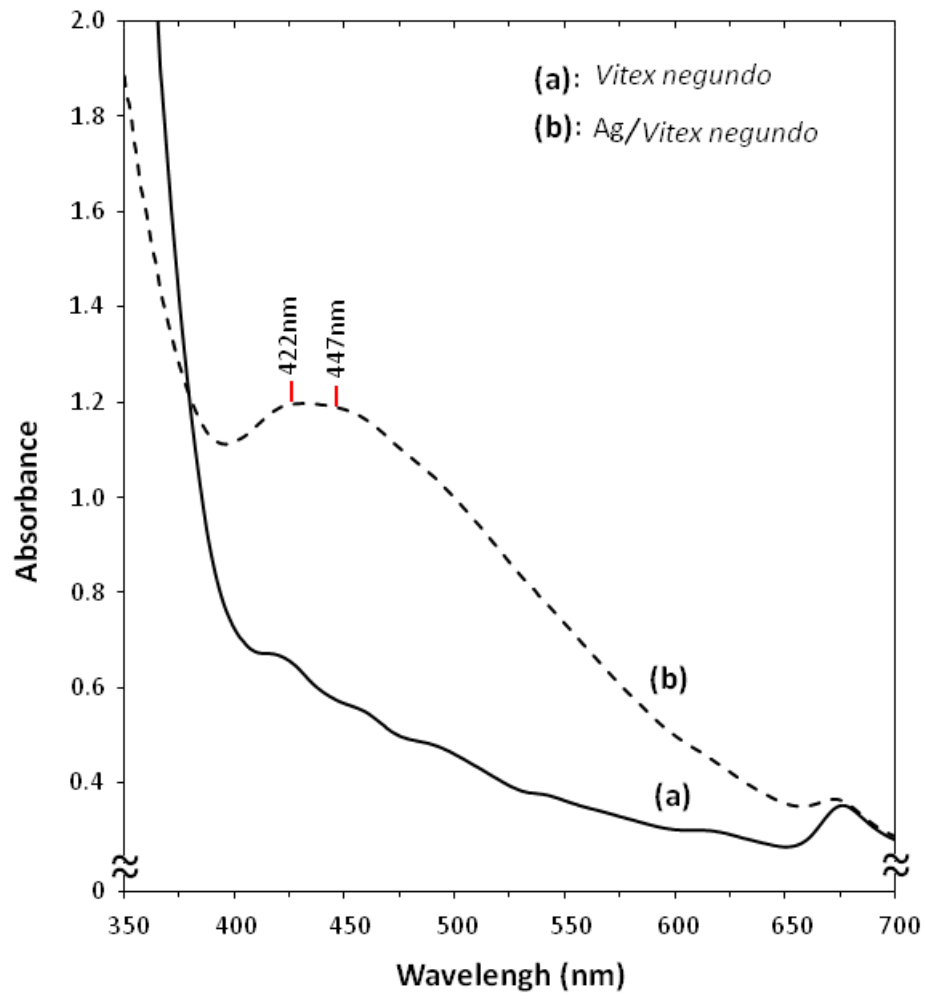

Figure 3 shows the X-ray diffraction (XRD) patterns of vacuum-dried silver nanoparticles synthesized using Vitex negundo. The XRD patterns of Ag/Vitex negundo indicated that the structure of silver nanoparticles is face-centered cubic (fcc) [36]. In addition, the silver nanoparticles had a similar diffraction profile and the XRD peaks at $2 \theta$ of $38.17^{\circ}, 44.31^{\circ}, 64.44^{\circ}, 77.34^{\circ}$ and $81.33^{\circ}$ could be attributed to the $111,200,220,311$ and 222 crystallographic planes of the face-centered cubic (fcc) silver crystals, respectively [37].

Figure 3. XRD patterns of Ag-NPs synthesized in Vitex negundo for determination of silver crystals after $48 \mathrm{~h}$.

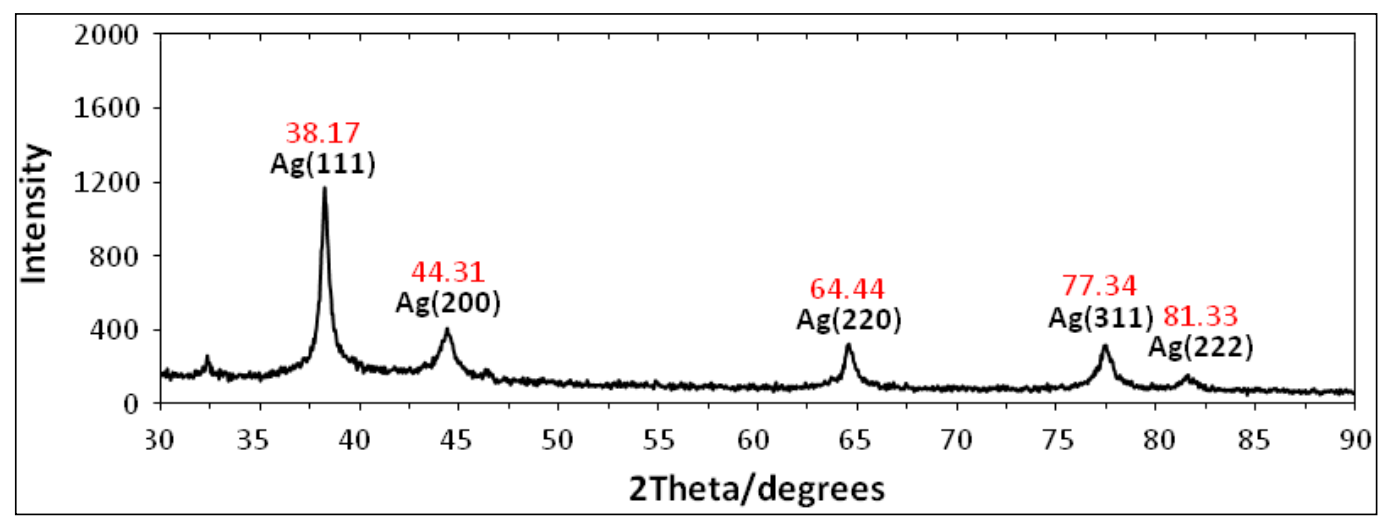


The XRD pattern thus clearly illustrated that the silver nanoparticles formed in the study are crystalline in nature. The main crystalline phase was silver and there was no obvious other phases as impurities were found in the XRD patterns (Ag XRD Ref. No. 01-087-0719).

For the transmission electron microscopy (TEM) study, a drop of the silver nanoparticles solution synthesized by treating silver nitrate solution with Vitex negundo was deposited onto a TEM grid which was coated with carbon support film. After drying, this grid was imaged using TEM. Figure 4 shows a representative TEM image, with an enlargement on its right side. The TEM image and their size distribution showed that the main diameter and standard deviation of silver nanoparticles $(18.2 \pm 8.9 \mathrm{~nm})$. The result showed two broad size distribution of particles, with diameter in the range of 10-20 $\mathrm{nm}$ and some larger diameter and uneven shapes in rang of 25-30 $\mathrm{nm}$. The presence of two broad distributions of particles in TEM image is in accordance with the UV-Vis spectral study [38].

Growth inhibition zones values were obtained in millimeter for the synthesized Ag/Vitex negundo nanoparticles against $E$. coli and $S$. aureus. The results of the study presented in Figure 5 and Table 1. Vitex negundo extract $(0.5 \mathrm{mg} / \mathrm{mL})$ did not have any antibacterial effect (Figure $5 \mathrm{a}_{1}$ and $5 \mathrm{~b}_{1}$ ). However, after formation of nanosilver, $\mathrm{Ag} /$ Vitex negundo emulsion has shown high antibacterial effect. The results presented in Figure $5 \mathrm{a}_{3}$ and $5 \mathrm{~b}_{3}$ showed the antibacterial effects of $\mathrm{Ag} /$ Vitex negundo against $E$. coli and $S$. aureus, respectively.

Figure 4. TEM image and corresponding size distribution of $\mathrm{Ag} /$ Vitex negundo after $48 \mathrm{~h}$.

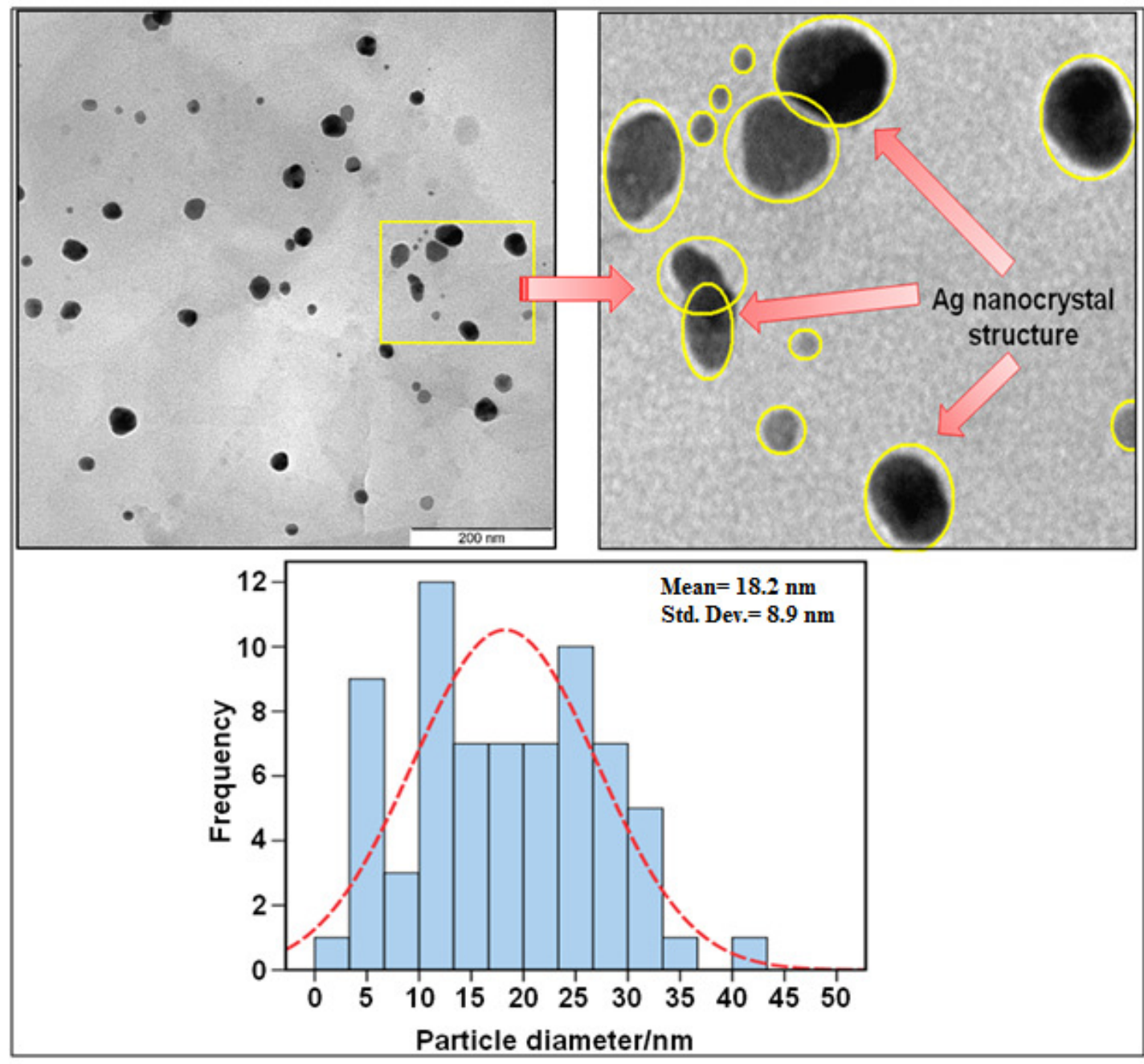


Table 1. Average of inhibition zones synthesized Ag/Vitex negundo nanoparticles.

\begin{tabular}{lcccc}
\hline \multirow{2}{*}{ Bacteria } & \multicolumn{2}{c}{ Inhibition zone diameter $(\mathbf{m m})$} & Control positive (mm) \\
\cline { 2 - 5 } & $\begin{array}{c}\text { Vitex negundo } \\
(0.5 \mathrm{mg} / \mathrm{mL})\end{array}$ & $\begin{array}{c}\mathrm{AgNO}_{3} \\
(0.17 \mathrm{~mol} / \mathrm{lit})\end{array}$ & $\mathrm{Ag} /$ Vitex negundo & $\begin{array}{c}\text { Cefotaxime } \\
(30 \mu \mathrm{g} / \mathrm{disc})\end{array}$ \\
\hline E. coli & 0.0 & $9.0 \pm 0.5$ & $12.0 \pm 0.7$ & $28.0 \pm 0.5$ \\
S. aureus & 0.0 & $9.5 \pm 0.5$ & $11.0 \pm 0.3$ & $21.0 \pm 1.5$ \\
\hline
\end{tabular}

Figure 5. Antibacterial activity assay against $E$. coli $\left(\mathrm{a}_{1}-\mathrm{a}_{4}\right)$ and $S$. aureus $\left(\mathrm{b}_{1}-\mathrm{b}_{4}\right):\left(\mathrm{a}_{1}, \mathrm{~b}_{1}\right)$ Vitex negundo extract $(0.5 \mathrm{mg} / \mathrm{mL}),\left(\mathrm{a}_{2}, \mathrm{~b}_{2}\right) \mathrm{AgNO}_{3}(0.17 \mathrm{~mol} / \mathrm{L}),\left(\mathrm{a}_{3}, \mathrm{~b}_{3}\right) \mathrm{Ag} /$ Vitex negundo, $\left(\mathrm{a}_{4}, \mathrm{~b}_{4}\right)$ Cefotaxime $(30 \mu \mathrm{g})$.
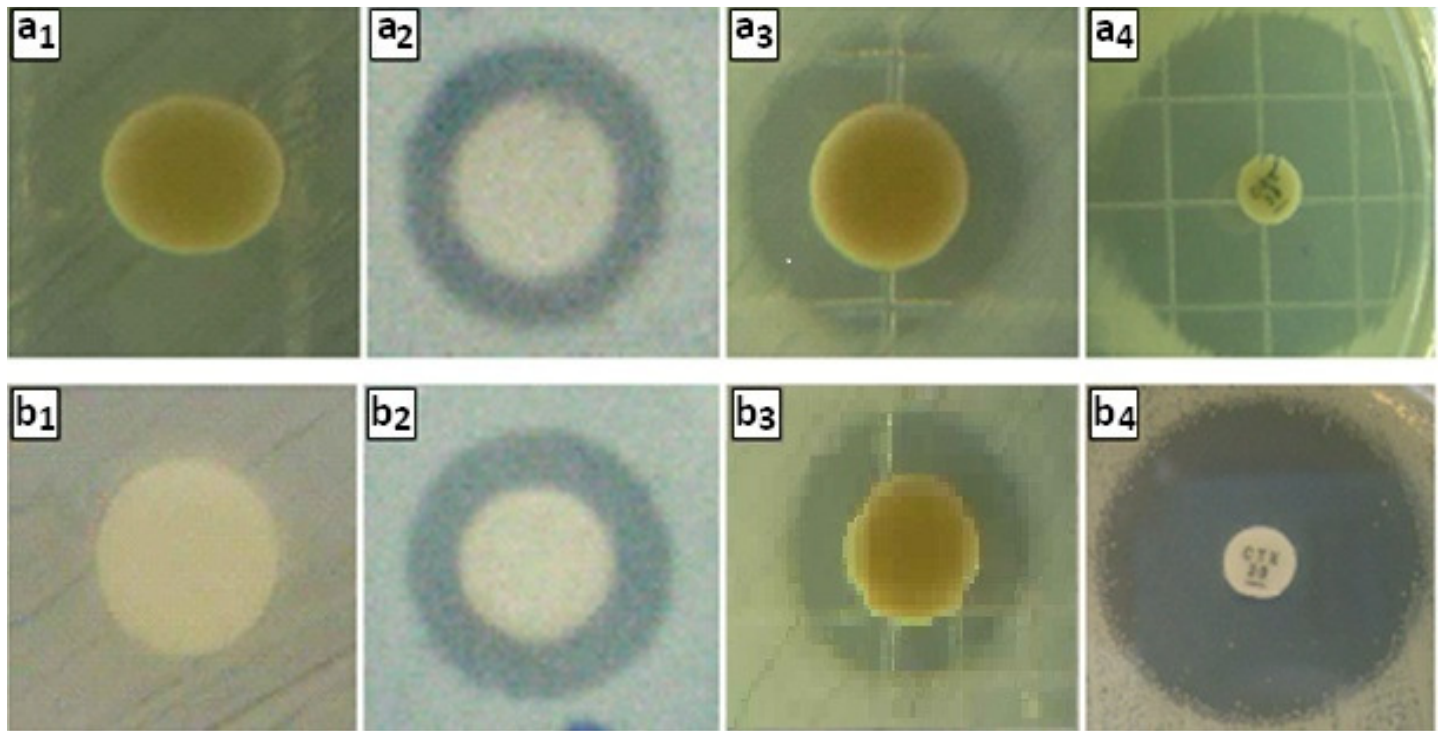

\section{Experimental}

\subsection{Materials}

Mature leaves of Vitex negundo were collected from the herbal unit of the Agriculture Park of Universiti Putra Malaysia (UPM). Methanol $\left(\mathrm{CH}_{3} \mathrm{OH}, 99.9 \%\right), \mathrm{AgNO}_{3}(99.98 \%)$, nutrient agar and Mueller-Hinton agar (MHA) were purchased from Merck (Germany). All aqueous solutions were prepared using double distilled water. All reagents used were of analytical grade.

\subsection{Extract Preparation}

Vitex negundo green leaves were washed and dried in an oven dryer at $40{ }^{\circ} \mathrm{C}$ for $48 \mathrm{~h}$. The dried leaves were then ground into powder, stored in dark glass bottles and kept at $-20{ }^{\circ} \mathrm{C}$ until further analyses. The finely ground Vitex negundo leaves $(20 \mathrm{~g})$ were extracted with methanol (ratio 1:10 w/v) overnight at $40{ }^{\circ} \mathrm{C}$ using a shaking water bath (Protech, Malaysia). After filtration with Whatman filter paper No 1 using vacuum pump, the residue was re-extracted. The solvent was completely removed using a rotary vacuum evaporator (Buchi, Flavil, Switzerland) at $40{ }^{\circ} \mathrm{C}$. The concentrated extract was then kept in dark bottles at $4{ }^{\circ} \mathrm{C}$ until used. 


\subsection{Synthesis of Ag/Vitex Negundo Emulsion}

Briefly, crude extract of Vitex negundo $(0.5 \mathrm{~g})$ was added to distilled de-ionized water (100 $\mathrm{mL})$ with vigorous stirring for $1 \mathrm{~h}$. A hundred milliliters of $\operatorname{AgNO}_{3}\left(1 \times 10^{-1} \mathrm{M}\right)$ was then added and mixed at room temperature $\left(25^{\circ} \mathrm{C}\right)$ for $48 \mathrm{~h}$. Silver nanoparticles were gradually obtained during the incubation period.

\subsection{Evaluation of Antibacterial Activity}

In vitro antibacterial activity of the prepared nanoparticles was evaluated using the Kirby-Bauer [39] technique, which conformed to the recommended standards of the National Committee for Clinical Laboratory Standards (NCCLS) (now known as Clinical and Laboratory Standards Institute CLSI). One species each of a Gram positive (Staphylococcus aureus ATCC 25923) and Gram negative bacteria (Escherichia coli ATCC 25922) were used for the antibacterial assay. Briefly, sterile paper discs $(6 \mathrm{~mm})$ impregnated with $\mathrm{Ag} /$ Vitex negundo $(20 \mu \mathrm{L})$ were left to dry at $30{ }^{\circ} \mathrm{C}$ for $24 \mathrm{~h}$ in an incubator. Several isolated colonies of bacteria were selected from a culture of 12-18 h on nutrient agar (Merck, Germany) and dissolved in sterile saline. The suspension was adjusted to match the tube $0.5 \mathrm{McFarland}$ turbidity standard using spectrophotometer in $600 \mathrm{~nm}$, which equal to $1.5 \times 10^{8}$ colony forming unit (CFU) per mL. The surface of MHA was completely cultured using a cotton swab which steeped in prepared suspension of bacterium. Finally, dried impregnated discs were placed on inoculated medium and incubated in $37{ }^{\circ} \mathrm{C}$ for $18-24 \mathrm{~h}$. The diameter of zone inhibition was measured in millimeter, and was recorded as mean $\pm \mathrm{SD}$ of the triplicate experiment. Cefotaxime $(30 \mu \mathrm{g}) \mathrm{was}$ used as positive standard for comparison purposes.

\subsection{Characterization Methods and Instruments}

The synthesized silver nanoparticles in Vitex negundo were characterized using X-ray diffraction, transmission electron microscopy and Ultraviolet-Visible spectroscopy. The structure of the silver nanoparticles was studied using the X-ray diffraction (XRD, Philips, X'pert, $\mathrm{Cu} \mathrm{K \alpha}$ ) at a scanning speed of $4 \% \mathrm{~min}$. The TEM observations were carried out using Hitachi H-7100 electron microscope, and the particle size distributions were determined using the UTHSCSA Image Tool version 3.00 programmed. The UV-Vis spectra were recorded over the range of 300-700 nm with a UV-visible spectrophotometer (H.UV 1650 PC-Shimadzu B.).

\section{Conclusions}

Nano-silver particles with an average size of $18.2 \pm 8.9 \mathrm{~nm}$ and spherical shapes were synthesized using methanolic extract of Vitex negundo leaf. The Ag-NPs were characterized by UV-Visible, TEM and XRD measurements. Synthesis of Ag/NPs using green resources like Vitex negundo is a better alternative to chemical synthesis, since this green synthesis is pollutant free and eco-friendly. The results suggested that Vitex negundo plays an important role in the reduction and stabilization of silver to silver nanoparticles. Study also found that the Ag/vitex negundo shows antibacterial activity on both Gram positive and Gram negative bacteria and should be explored further for antimicrobial applications. 


\section{Acknowledgments}

The authors would like to acknowledge The Ministry of Science, Technology and Innovation (MOSTI) of Malaysia for financing the project, Department of Chemistry, Institute of Bioscience and Faculty of Food Science and Technology, Universiti Putra Malaysia, for the laboratory facilities.

\section{References}

1. Gurunathan, S.; Kalishwaralal, K.; Vaidyanathan, R.; Deepak, V.; Pandian, S.R.K.; Muniyandi, J. Biosynthesis, purification and characterization of silver nanoparticles using Escherichia coli. Colloids Surf. B 2009, 74, 328-335.

2. Jain, D.; Daima, H.K.; Kachhwaha, S.; Kothari, S.L. Synthesis of plant-mediated silver nanoparticles using papaya fruit extract and evaluation of their anti microbial activities. Dig. J. Nanomater. Biostruct. 2009, 4, 723-727.

3. Jiang, Z.J.; Liu, C.Y.; Sun, L.W. Catalytic properties of silver nanoparticles supported on silica spheres. J. Phys. Chem. B. 2005, 109, 1730-1735.

4. Joerger, T.K.; Joerger, R.; Olsson, E.; Granqvist, C.G. Bacteria as workers in the living factory: Metal-accumulating bacteria and their potential for materials science. Trends Biotechnol. 2001, $19,15-20$.

5. Moulin, E.; Sukmanowski, J.; Schulte, M.; Royer, F.X.; Stiebig, H. Thin-film silicon solar cells with integrated silver nanoparticles. Thin Solid Films 2008, 516, 6813-6817.

6. Nam, J.M.; Park, S.J.; Mirkin, C.A. Bio-barcodes based on oligonucleotide modified nanoparticles. J. Am. Chem. Soc. 2002, 124, 3820-3821.

7. Aymonier, C.; Schlotterbeck, U.; Antonietti, L.; Zacharias, P.; Thomann, R.; Tiller, J.C.; Mecking, S. Hybrids of silver nanoparticles with amphiphilic hyperbranched macromolecules exhibiting antimicrobial properties. Chem. Commun. 2002, 24, 3018-3019.

8. Songping, W.; Shuyuan, M. Preparation of ultrafine silver powder using ascorbic acid as reducing agent and its application in MLCI. Mater. Chem. Phys. 2005, 89, 423-427.

9. Parvulescu, V.I.; Cojocaru, B.; Parvulescu, V.; Richards, R.; Li, Z.; Cadigan, C.; Granger, P.; Miquel, P.; Hardacre, C. Sol-gel-entrapped nano silver catalysts-correlation between active silver species and catalytic behavior. J. Catal. 2010, 272, 92-100.

10. Murthy, Y.L.N.; Rao, T.K.; Viswanath, I.V.K.; Singh, R. Synthesis and characterization of nano silver ferrite composite. J. Magn. Magn. Mater. 2010, 322, 2071-2074.

11. Sharma, V.K.; Yngard, R.A.; Lin, Y. Silver nanoparticles: Green synthesis and their antimicrobial activities. Adv. Colloid Interface Sci. 2009, 145, 83-96.

12. Vigneshwaranm, N.; Ashtaputre, N.M.; Varadarajan, P.V.; Nachane, R.P.; Paralikar, K.M.; Balasubramanya, R.H. Biological synthesis of silver nanoparticles using the fungus Aspergillus flavus. Mater. Lett. 2007, 61, 1413-1418.

13. Mohanpuria, P.; Rana, N.K.; Yadav, S.K. Biosynthesis of nanoparticles: Technological concepts and future applications. J. Nanopart. Res. 2008, 10, 507-517.

14. Shankar, S.S.; Rai, A.; Ahmad, A.; Sastry, M.J. Rapid synthesis of Au, Ag, and bimetallic Au core-Ag shell nanoparticles using Neem (Azadirachta indica) leaf broth. J. Colloid Interface Sci.

2004, 275, 496-502. 
15. Mukherjee, P.; Ahmad, A.; Mandal, D.; Senapati, S.; Sainkar, S.R.; Khan, M.I.; Ramani, R.; Parischa, R.; Ajaykumar, P.V.; Alam, M.; et al. Bioreduction of $\mathrm{AuCl}_{4}{ }^{-}$Ions by the Fungus, Verticillium sp. and surface trapping of the gold nanoparticles formed. Angew. Chem. Int. Ed. 2001, 40, 3585-3588.

16. Mukherjee, P.; Ahmad, A.; Mandal, D.; Senapati, S.; Sainkar, S.R.; Khan, M.I.; Parischa, R.; Ajayakumar, P.V.; Alam, M.; Kumar, R.; et al. Fungus-mediated synthesis of silver nanoparticles and their immobilization in the mycelial matrix: A novel biological approach to nanoparticle synthesis. Nano Lett. 2001, 1, 515-519.

17. Medina-Ramirez, I.; Bashir, S.; Luo, Z.P.; Liu, J.L. Green synthesis and characterization of polymer-stabilized silver nanoparticles. Colloids Surf. B 2009, 73, 185-191.

18. Konishi, Y.; Nomura, T.; Tsukiyama, T.; Saitoh, N. Microbial preparation of gold nanoparticles by anaerobic bacterium. Trans. Mater. Res. Soc. Jpn. 2004, 29, 2341-2343.

19. Leela, A.; Vivekanandan, M. Tapping the unexploited plant resources for the synthesis of silver nanoparticles. Afr. J. Biotechnol. 2008, 7, 3162-3165.

20. Chandran, S.P.; Chaudhary, M.; Pasricha, R.; Ahmad, A.; Sastry, M. Synthesis of gold nanotriangles and silver nanoparticles using Aloe vera plant extract. Biotechnol. Prog. 2006, 22, 577-583.

21. Gardea-Torresdey, J.L.; Gomez, E.; Peralta-Videa, J.R.; Parsons, J.G.; Troiani, H.E.; Santiago, P. Alfalfa sprouts: A natural source for the synthesis of silver nanoparticles. Langmuir 2003, 19, 1357-1361.

22. Li, S.; Shen, Y.; Xie, A.; Yu, X.; Qiu, L.; Zhang, L.; Zhang, Q. Green synthesis of silver nanoparticles using Capsicum annuum L. extract. Green Chem. 2007, 9, 852-858.

23. Song, J.Y.; Jang, H.K.; Kim, B.S. Biological synthesis of gold nanoparticles using Magnolia kobus and Diopyros kaki leaf extracts. Process Biochem. 2009, 44, 1133-1138.

24. Huang, J.; Li, Q.; Sun, D.; Lu, Y.; Su, Y.; Yang, X.; Wang, H.; Wang, Y.; Shao, W.; He, N.; Hong, J.; Chen, C. Biosynthesis of silver and gold nanoparticles by novel sundried Cinnamomum camphora leaf. Nanotechnology 2007, 18, 105104-105115.

25. Shankar, S.S.; Rai, A.; Ahmad, A.; Sastry, M. Biosynthesis of silver and gold nanoparticles from extracts of different parts of the geranium plant. Appl. Nano Sci. 2004, 1, 69-77.

26. Dubey, M.; Bhadauria, S.; Kushwah, B.S. Green synthesis of nanosilver particles from extract of Eucalyptus Hybrida (Safeda) leaf. Dig. J. Nanomater. Biostruct. 2009, 4, 537-543.

27. Prabhu, N.; Raj, D.T.; Yamuna, G.K.; Siddiqua, S.A.; Innocent, J.P. Synthesis of silver phyto nanoparticles and their anti-bacterial efficacy. Dig. J. Nanomater. Biostruct. 2010, 5, 185-189.

28. Mustafa, R.A.; Abdul Hamid, A.; Mohamed, S.; Abu Bakar, F. Total phenolic compounds, flavonoids and radical scavenging activity of selected tropical plants. J. Food Sci. 2010, 75, C28-C35.

29. Ling, T.J.; Ling, W.W.; Chen, Y.J.; Wan, X.C.; Xia, T.; Du, X.X.; Zhang, Z.Z. Antiseptic activity and phenolic constituents of the aerial parts of Vitex negundo var. cannabifolia. Molecules $\mathbf{2 0 1 0}$, $15,8469-8477$.

30. Ahmad, M.B.; Shameli, K.; Darroudi, M.; Yunus, W.M.Z.W.; Ibrahim, N.A.; Hamid, A.A.; Zargar, M. Antibacterial activity of silver/clay/chitosan bionanocomposites. Res. J. Biol Sci. 2009, 4, 1156-1161. 
31. Chamakura, K.; Perez-Ballestero, R.; Luo, Z.P.; Bashir, S.; Liu, J. Comparison of bactericidal activities of silver nanoparticles with common chemical disinfectants. Colloids Surf. B 2011, 84, 88-96.

32. Medina-Ramirez, I.; Luo, Z.P.; Bashir, S.; Mernaugh, R.; Liu, J.L. Facile design and nanostructural evaluation of silver-modified titania used as disinfectant. Dalton Trans. 2011, 40, 1047-1054.

33. Magana, S.M.; Quintana, P.; Aguilar, D.H.; Toledo, J.A.; Angeles-Chavez, C.; Cortes, M.A.; Leon, L.; Freile-Pelegrin, Y.; Lopez, T.; Torres Sanchez, R.M. Antibacterial activity of montmorillonites modified with silver. J. Mol. Catal. A Chem. 2008, 281, 192-199.

34. Nithya, R.; Ragunathan, R. Synthesis of silver nanoparticle using Pleurotus sajor caju and its antimicrobial study. Dig. J. Nanomater. Biostruct. 2009, 4, 623-629.

35. Lara, H.H.; Nuñez, N.V.A.; Turrent, L.I.; Rodriguez-Padilla, C. Mode of antiviral action of silver nanoparticles against HIV-1. J. Nanobiotechnol. 2010, 8, 1-10.

36. Shameli, K.; Ahmad, M.B.; Yunus, W.M.Z.W.; Ibrahim, N.A. Synthesis and characterization of silver/talc nanocomposites using the wet chemical reduction method. Int. J. Nanomed. 2010, 5, 743-751.

37. Shameli, K.; Ahmad, M.B.; Yunus, W.M.Z.W.; Ibrahim, N.A.; Zargar, M. Synthesis of silver nanoparticles in montmorillonite and their antibacterial behaviour. Int. J. Nanomed. 2011, 6, $581-590$.

38. Philip, D. Green synthesis of gold and silver nanoparticles using Hibiscus rosa sinensis. Phys. E 2010, 42, 1417-1424.

39. Bauer, A.W.; Kirby, W.M.; Sherris, J.C.; Turck, M. Antibiotic susceptibility testing by a standardized single disk method. Am. J. Clin. Pathol. 1966, 45, 493-496.

Sample Availability: Samples of the compounds are available from the authors.

(C) 2011 by the authors; licensee MDPI, Basel, Switzerland. This article is an open access article distributed under the terms and conditions of the Creative Commons Attribution license (http://creativecommons.org/licenses/by/3.0/). 